\title{
Emergency surgery in complex incisional hernias management
}

\author{
Chirurgia de urgenţă în managementul herniilor postincizionale complexe
}

\begin{tabular}{|c|}
\hline $\begin{array}{c}\text { Roxana-Florina Ristea1, Nicoleta-Aurelia Sanda², Daniel Ion }{ }^{3,4} \text {, } \\
\text { Marius-Răzvan Ristea }{ }^{4} \text {, Radu Şerban Palade }{ }^{5}\end{array}$ \\
\hline $\begin{array}{l}{ }^{1} \text { Chirurgie Generală, Spitalul Euroclinic, Bucureşti, România } \\
{ }^{2} \text { Chirurgie Generală II, Spitalul Universitar de Urgenţă, Bucureşti, România } \\
{ }^{3} \text { Chirurgie Generală III, Spitalul Universitar de Urgenţă, Bucureşti, România } \\
\text { 4Chirurgie Plastică şi Microchirurgie Reconstructivă, Spitalul Universitar de Urgenţă, Bucureşti, România } \\
{ }^{5} \text { UMF „Carol Davila“, Bucureşti, România }\end{array}$ \\
\hline
\end{tabular}

\begin{abstract}
Introduction. Complex incisional hernias are a surgical challenge and a current socio-economic problem. In the emergency surgery of this pathology, the surgeon faces the need to obtain a "tension-free" hernia repair being limited in the use of parietal prosthesis due to the frequent needs of opening the gastrointestinal tract and thus contamination of the operating field.

Purpose. The aim of this study is to evaluate and adapt emergency surgical treatment in order to reduce the risk of postoperative complications.

Material and methods. The present study has a retrospective character and evaluates a group of 390 patients with complex incisional hernias admitted and operated in the General and Emergency Surgery III section of the Bucharest University Emergency Hospital during 2008-2018.

Results. We identified 390 patients diagnosed with complex incisional hernias, of whom 95 were presented to the hospital as an emergency. The prosthetic hernioraphy was used in 51 of these patients, and complications were found in 18 patients in the total study group, ranging from wound infection to death.

Discussions. The occurrence of postoperative complications was not statistically significantly associated with emergency surgical treatment. Instead, vital complications were much more common in this group.

Conclusions. Increasing the degree of information and education of the patient, increasing addressability and avoiding emergency operations for this pathology are long-term objectives in the treatment of complex incisional hernia pathology.
\end{abstract}

Keywords: complex incisional hernias, emergency, prosthesis, complications

\section{REZUMAT}

Introducere. Herniile postincizionale complexe reprezintă o provocare chirurgicală şi o problemă socio-economică actuală. În chirurgia de urgenţă a acestei patologii, chirurgul se confruntă cu necesitatea de a obţine o reparaţie herniară "tension-free" fiind limitat în utilizarea protezării parietale din cauza necesităţii frecvente a deschiderii tractului gastrointestinal şi secundar a contaminării câmpului operator.

Obiective. Scopul lucrării este reprezentat de evaluarea şi adaptarea tratamentului chirurgical de urgenţă în vederea reducerii riscului de complicaţii postoperatorii.

Material şi metode. Studiul de faţă este unul retrospectiv şi evaluează un lot de 390 de pacienţi cu hernii postincizionale complexe internaţi şi operaţi în secţia de Chirurgie Generală şi Urgenţă III a Spitalului Universitar de Urgenţă Bucureşti în perioada 2008-2018.

Rezultate. Am identificat 390 de pacienţi diagnosticaţi cu hernii postincizionale complexe, dintre care $95 \mathrm{~s}$-au prezentat la spital în regim de urgenţă. Protezarea a fost utilizată la 51 dintre aceşti pacienţi, iar complicaţiile au fost întâlnite la 18 pacienţi din lotul total de studiu, mergând de la supuraţii de plagă până la deces.

Discuţii. Apariţia complicaţiilor postoperatorii nu s-a asociat semnificativ statistic cu tratamentul chirurgical de urgenţă. În schimb, complicaţiile vitale au fost mult mai frecvente la aceşti pacienţi.

Concluzii. Creşterea gradului de informare şi educare a pacientului, creşterea adresabilităţii şi evitarea operaţiilor de ugenţă pentru această patologie reprezintă obiective pe termen lung în tratamentul patologiei herniare postincizionale complexe.

Cuvinte cheie: hernii postincizionale complexe, urgenţă, protezare, complicaţii 


\section{INTRODUCERE}

Herniile postincizionale, patologie frecvent întâlnită în chirurgia generală, reprezintă încă o provocare în ceea ce priveşte procedeul reparator utilizat. Frecvenţa crescută a acestei complicaţii evolutive a unei laparotomii, de până la 20\% (1-3), reprezintă o problemă socio-economică de actualitate, dat fiind numărul intervenţiilor corectoare efectuate anual şi costurilor asociate acestora.

Herniile postincizionale reprezintă migrarea viscerelor intra sau retroperitoneale în afara cavităţii abdominale printr-un defect musculo-aponevrotic situat în afara zonelor slabe herniare, la nivelul sau în vecinătatea unei incizii chirurgicale. Acestea apar prin deteriorarea arhitecturii peretelui musculo-aponevrotic sau pot fi generate de o vindecare improprie a unei linii de incizie a peretelui abdominal $(4,5)$.

În prezent, termenul de hernie postincizională complexă nu recunoaşte o definiţie unanim acceptată. Aceste tipuri de hernii întrunesc existenţa unor factori de risc general, particularităţi anatomice şi existenţa unui proces supurativ în vindecarea vechii laparotomii (6).

Chirurgia de urgenţă în reparaţia herniară postincizională, în contextul apariţiei complicaţiilor evolutive ale acestei patologii, de tipul încarcerării sau strangulării, pune probleme tehnice deosebite.

Având în vedere tabloul clinic al ocluziilor intestinale generate de strangularea sau încarcerarea conţinutului intestinal, chirurgul se confruntă cu structuri aponevrotice friabile, inflamate, cu edem important (7). De asemenea, în multe dintre cazuri este necesară asocierea unor rezecţii intestinale, implicând realizarea unei cure herniare postincizionale într-un câmp operator contaminat, ceea ce de multe ori face imposibilă protezarea parietală (8-11).

În acest context, herniile postincizionale operate în condiţii de urgenţă, în momentul apariţiei complicaţiilor, sunt grevate de un risc de infecţios de $10 \%$ până la $35 \%(12-14)$.

Folosirea materialelor protetice în reparaţia herniară postincizională şi-a demonstrat superioritatea în ceea ce priveşte complicaţiile şi recidiva (15), asigurând dezideratul de reparaţie lipsită de tensiune (16), dar, în condiţiile utilizării protezelor în asociere cu deschiderea tractului gastrointestinal, aceste tehnici se confruntă cu o rată mare de complicaţii infecţioase $(14,17-20)$.

Cura chirurgicală a herniilor postincizionale în manieră aloplastică şi-a demonstrat superioritatea în ceea ce priveşte complicaţiile şi recidiva, dar, în cazul chirurgiei de urgenţă, trebuie utilizată cu prudenţă (21-26).

\section{SCOP}

Studiul de faţă îşi propune să raporteze practica serviciului nostru în tratamentul herniilor postincizionale complexe operate în urgenţă, să identifice şi să evalueze complicaţiile postoperatorii, să evalueze beneficiile şi riscurile herniorafiei aloplastice, în vederea adaptării procedeelor chirurgicale utilizate în urgenţă.

\section{MATERIAL ŞI METODE}

Pentru aprofundarea acestei patologii, au fost evaluaţi 617 pacienţi internaţi şi operaţi în Clinica de Chirurgie III a Spitalului Universitar de Urgenţă Bucureşti în perioada 2008-2018.

Studiul are un caracter retrospectiv, informaţiile fiind obţinute din cercetarea foilor de observaţie clinică, rezultatele investigaţiilor paraclinice, cercetarea protocoalelor operatorii.

Pacienţii incluşi în studiu au fost cei cu diagnostic principal de hernie postincizională a peretelui abdominal antero-lateral, care au întrunit criteriile de definire ale European Hernia Society (EHS - Societatea Europeană de Herniologie) pentru încadrarea în subgrupul herniilor postincizionale complexe şi au beneficiat de tratament chirurgical.

Criteriile de excludere din studiu au fost reprezentate de pacienţii la care s-a optat pentru tratament nonoperator, ca urmare a riscului anestezicochirurgical major sau care au refuzat intervenţia chirurgicală.

TABEL 1. Clasificarea EHS a herniilor postincizionale complexe (1)

\begin{tabular}{|c|c|c|c|}
\hline $\begin{array}{l}\text { Herniile } \\
\text { postincizionale de } \\
\text { linie mediană }\end{array}$ & $\begin{array}{l}\text { Subxifoidiene } \\
\text { Epigastrice } \\
\text { Ombilicale } \\
\text { Subombilicale } \\
\text { Suprapubiene }\end{array}$ & $\begin{array}{l}\text { M1 } \\
\text { M2 } \\
\text { M3 } \\
\text { M4 } \\
\text { M5 }\end{array}$ & \\
\hline $\begin{array}{l}\text { Herniile } \\
\text { postincizionale } \\
\text { laterale }\end{array}$ & $\begin{array}{l}\text { Subcostale } \\
\text { Flancuri } \\
\text { Iliace } \\
\text { Lombare }\end{array}$ & $\begin{array}{l}\text { L1 } \\
\text { L2 } \\
\text { L3 } \\
\text { L4 }\end{array}$ & \\
\hline \multirow{2}{*}{$\begin{array}{l}\text { Hernie } \\
\text { postincizională } \\
\text { recidivată? }\end{array}$} & ${ }_{0}^{D a}$ & $\begin{array}{l}\mathrm{Nu} \\
\mathrm{O}\end{array}$ & \\
\hline & Lungime ...cm & Lăţime ...cm & \\
\hline Lăţime & $\begin{array}{l}\mathbf{W} 1 \\
<4 \mathrm{~cm} \\
0\end{array}$ & $\begin{array}{l}\mathbf{W} 2 \\
\geq 4-10 \mathrm{~cm} \\
0\end{array}$ & $\begin{array}{l}\text { W3 } \\
\geq 10 \mathrm{~cm} \\
0\end{array}$ \\
\hline
\end{tabular}

Pentru fiecare pacient în parte a fost întocmită o foaie de studiu. Datele obţinute au fost apoi centralizate şi prelucrate statistic. 
Baza de date a fost generată folosind Microsoft Excel 14.0.4760.1000, iar analiza descriptivă şi statistică a fost realizată cu SPSS (Statistical Package for the Social Sciences), versiunea IBM SPSS statistics 2015. Reprezentarea grafică a fost obţinută cu ajutorul Microsoft Excel 14.0.4760.1000 şi GraphPad Prism 8.0.0.

Din lotul total de 617 pacienţi, 390 au îndeplinit criteriile de includere în lotul pacienţilor cu hernii postincizionale complexe, iar dintre aceştia, 95 au necesitat tratament chirurgical de urgenţă.

\section{REZULTATE}

Dintre cei 390 de pacienţi diagnosticaţi cu hernii postincizionale complexe, $95 \mathrm{~s}-\mathrm{au}$ prezentat la spital în regim de urgenţă, de cele mai multe ori în momentul încarcerării sau strangulării conţinutului herniar.

Intervenţia chirurgicală realizată în urgenţă, context în care există posibilitatea asocierii unui proces infecţios intraperitoneal, a unei necroze intestinale sau parietale, a necesităţii asocierii deschiderii tractului bilio-digestiv şi în care, de multe ori, este evitată alegerea unei tehnici chirurgicale aloplastice reparatorii, creşte riscul de complicaţii postoperatorii imediate şi la distanţă.

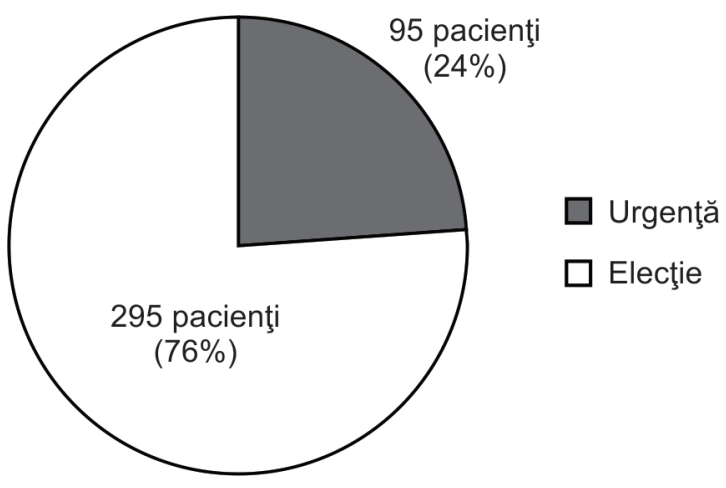

FIGURA 1. Modul de prezentare al pacienților cu hernii postincizionale complexe

Dintre bolnavii ce au necesitat intervenții chirurgicale corectoare cu caracter de urgenţă, 26\% au prezentat hernii complexe reductibile, $13,8 \%$ s-au prezentat în momentul strangulării şi $60 \% \mathrm{cu}$ hernii complexe încarcerate.

Evaluând tabloul clinic al pacienţilor prezentaţi la camera de gardă pentru o patologie herniară postincizională complexă, observăm că simptomatologia algică se regăseşte la toţi pacienţii ce se prezintă la spital de urgenţă în momentul apariţiei complicaţiilor. Această constatare se asociază semnificativ statistic cu modalitatea de prezentare şi momentul intervenţiei chirurgicale $(p=0,03)$.
TABEL 2 A,B. Distributia și corelatia distributiei simptomatologiei algice la pacienții operați în urgență

A. Distribuția simptomatologiei algice

\begin{tabular}{|c|c|c|c|c|c|}
\hline & \multicolumn{2}{|c|}{ Tipul operaţiei } & \multirow{2}{*}{ Total } \\
\hline & & & Elecţie & Urgenţă & \\
\hline \multirow[t]{8}{*}{ Durere } & \multirow[t]{4}{*}{ Absentă } & Count & 14 & 0 & 14 \\
\hline & & $\%$ within Durere & $100.0 \%$ & $0.0 \%$ & $100.0 \%$ \\
\hline & & $\begin{array}{l}\text { \% within Tipul } \\
\text { operaţiei }\end{array}$ & $4.7 \%$ & $0.0 \%$ & $3.6 \%$ \\
\hline & & $\%$ of Total & $3.6 \%$ & $0.0 \%$ & $3.6 \%$ \\
\hline & \multirow[t]{4}{*}{ Prezentă } & Count & 282 & 95 & 376 \\
\hline & & $\%$ within Durere & $75.0 \%$ & $25.0 \%$ & $100.0 \%$ \\
\hline & & $\begin{array}{l}\% \text { within Tipul } \\
\text { operaţiei }\end{array}$ & $95.3 \%$ & $100.0 \%$ & $96.4 \%$ \\
\hline & & $\%$ of Total & $72.3 \%$ & $24.1 \%$ & $96.4 \%$ \\
\hline \multirow{4}{*}{\multicolumn{2}{|c|}{ Total }} & Count & 296 & 95 & 390 \\
\hline & & $\%$ within Durere & $75.9 \%$ & $24.1 \%$ & $100.0 \%$ \\
\hline & & $\begin{array}{l}\% \text { within Tipul } \\
\text { operaţiei }\end{array}$ & $100.0 \%$ & $100.0 \%$ & $100.0 \%$ \\
\hline & & $\%$ of Total & $75.9 \%$ & $24.1 \%$ & $100.0 \%$ \\
\hline
\end{tabular}

B. Corelația distribuției simptomatologiei algice

\begin{tabular}{|c|c|c|c|}
\hline \multirow{4}{*}{$\begin{array}{l}\text { Tipul } \\
\text { operaţiei }\end{array}$} & & Tipul operaţiei & Durere \\
\hline & Pearson Correlation & 1 & $.109^{*}$ \\
\hline & Sig. (2-tailed) & & .032 \\
\hline & $N$ & 390 & 390 \\
\hline \multirow{3}{*}{ Durere } & Pearson Correlation & $.109^{*}$ & 1 \\
\hline & Sig. (2-tailed) & .032 & \\
\hline & $N$ & 390 & 390 \\
\hline
\end{tabular}

*. Correlation is significant at the 0.05 level (2-tailed)

Simptomatologia ocluzivă intestinală, mergând până la oprirea definitivă a tranzitului intestinal, a fost unul dintre principalele motive care au determinat bolnavii ce prezentau defecte herniare postincizionale complexe să se prezinte la spital. Această simptomatologie a fost întâlnită la 77,7\% dintre pacienţii operaţi în urgenţă, fapt relevant din punct de vedere statistic $(\mathrm{p}=0,0001)$.

TABEL 3A,B. Distribuția şi corelația distribuției simptomatologiei ocluzive la prezentarea în urgență

\section{A. Distribuția simptomatologiei ocluzive}

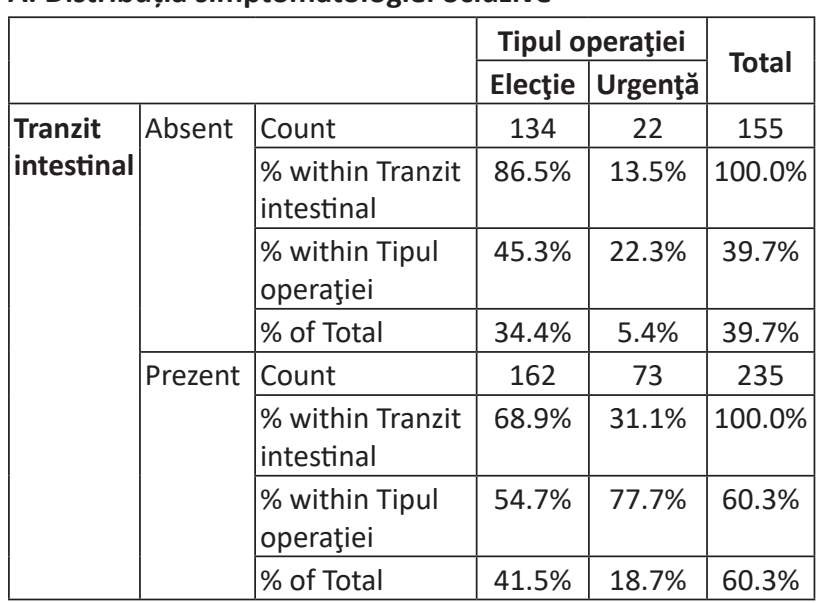




\begin{tabular}{|l|l|c|c|c|}
\hline \multicolumn{2}{|c|}{} & \multicolumn{2}{|c|}{ Tipul operaţiei } & \multirow{2}{*}{ Total } \\
\cline { 3 - 5 } \multicolumn{2}{|c|}{ Total } & Elecţie & Urgenţă & \\
\hline & Count & 296 & 95 & 390 \\
\cline { 2 - 5 } & $\begin{array}{l}\text { \% within Tranzit } \\
\text { intestinal }\end{array}$ & $75.9 \%$ & $24.1 \%$ & $100.0 \%$ \\
\cline { 2 - 5 } & $\begin{array}{l}\text { \% within Tipul } \\
\text { operaţiei }\end{array}$ & $100.0 \%$ & $100.0 \%$ & $100.0 \%$ \\
\cline { 2 - 5 } & $\%$ of Total & $75.9 \%$ & $24.1 \%$ & $100.0 \%$ \\
\hline
\end{tabular}

B. Corelația distribuției simptomatologiei ocluzive

\begin{tabular}{|l|l|c|c|}
\hline \multirow{4}{*}{\begin{tabular}{l}
\multirow{4}{*}{$\begin{array}{l}\text { Tipul } \\
\text { operaţiei }\end{array}$} \\
\cline { 2 - 4 }
\end{tabular}} & $\begin{array}{c}\text { Tipul } \\
\text { operaţiei }\end{array}$ & $\begin{array}{c}\text { Tranzit } \\
\text { intestinal }\end{array}$ \\
\cline { 2 - 4 } & Pearson Correlation & 1 & $.200^{* *}$ \\
\cline { 2 - 4 } & Sig. (2-tailed) & & .000 \\
\cline { 2 - 4 } $\begin{array}{l}\text { Tranzit } \\
\text { intestinal }\end{array}$ & Pearson Correlation & $.200^{* *}$ & 1 \\
\cline { 2 - 4 } & Sig. (2-tailed) & .000 & \\
\cline { 2 - 4 } & $\mathrm{N}$ & 390 & 390 \\
\hline
\end{tabular}

**. Correlation is significant at the 0.01 level (2-tailed)

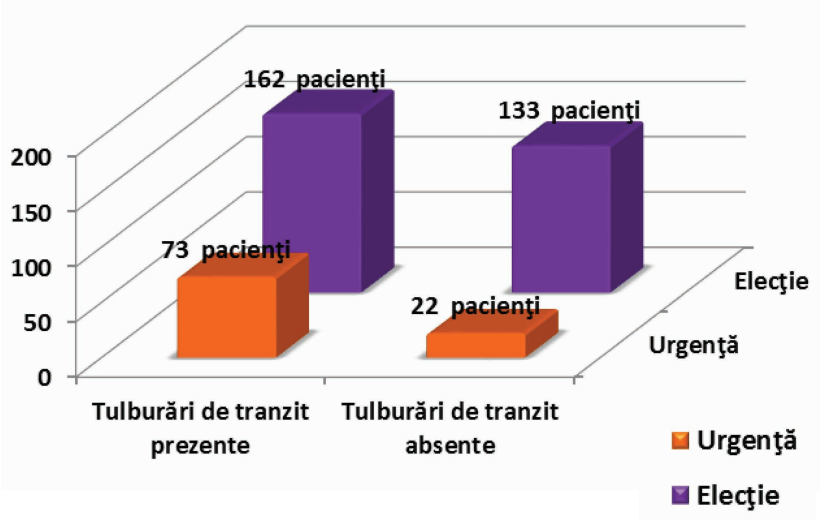

FIGURA 2. Asocierea simptomatologiei ocluzive cu prezentarea în urgență

În ceea ce privește tipul defectului parietal, am constatat că herniile multisaculare au evoluat mai frecvent către complicaţii ce au necesitat intervenții chirurgicale de urgenţă, comparativ cu defectele herniare unice $(68,8 \%$ din totalul herniilor postincizionale complexe complicate prin încarcerare şi $59,1 \%$ dintre herniile complexe strangulate).

TABEL 4A,B. Distribuția şi corelația distribuției caracteristicilor defectului herniar în raport cu rata complicațiilor evolutive

4A. Distribuția caracteristicilor defectului herniar

\begin{tabular}{|c|c|c|c|c|c|}
\hline & & & \multicolumn{2}{|c|}{ Tip Eventraţie } & \multirow{2}{*}{ Total } \\
\hline & & & Unisaculară & Multisaculară & \\
\hline \multirow[t]{12}{*}{ Taxis } & \multirow[t]{4}{*}{ Încarcerată } & Count & 74 & 163 & 237 \\
\hline & & $\%$ within Taxis & $31.2 \%$ & $68.8 \%$ & $100.0 \%$ \\
\hline & & $\%$ within Tip Eventraţie & $50.0 \%$ & $67.4 \%$ & $60.8 \%$ \\
\hline & & $\%$ of Total & $19.0 \%$ & $41.8 \%$ & $60.8 \%$ \\
\hline & \multirow[t]{4}{*}{ Reductibilă } & Count & 65 & 66 & 131 \\
\hline & & $\%$ within Taxis & $49.6 \%$ & $50.4 \%$ & $100.0 \%$ \\
\hline & & $\%$ within Tip Eventraţie & $43.9 \%$ & $27.3 \%$ & $33.6 \%$ \\
\hline & & $\%$ of Total & $16.7 \%$ & $16.9 \%$ & $33.6 \%$ \\
\hline & \multirow[t]{4}{*}{ Strangulată } & Count & 9 & 13 & 22 \\
\hline & & $\%$ within Taxis & $40.9 \%$ & $59.1 \%$ & $100.0 \%$ \\
\hline & & $\%$ within Tip Eventraţie & $6.1 \%$ & $5.4 \%$ & $5.6 \%$ \\
\hline & & $\%$ of Total & $2.3 \%$ & $3.3 \%$ & $5.6 \%$ \\
\hline \multirow{4}{*}{\multicolumn{2}{|c|}{ Total }} & Count & 148 & 242 & 390 \\
\hline & & $\%$ within Taxis & $37.9 \%$ & $62.1 \%$ & $100.0 \%$ \\
\hline & & \% within Tip Eventraţie & $100.0 \%$ & $100.0 \%$ & $100.0 \%$ \\
\hline & & $\%$ of Total & $37.9 \%$ & $62.1 \%$ & $100.0 \%$ \\
\hline
\end{tabular}

B. Corelația distribuției caracteristicilor defectului herniar

\begin{tabular}{|l|l|l|l|}
\hline \multirow{4}{*}{ Taxis } & & Taxis & Tip Eventraţie \\
\cline { 2 - 4 } & Pearson Correlation & 1 & $-.146^{* *}$ \\
\cline { 2 - 4 } & Sig. (2-tailed) & & .004 \\
\cline { 2 - 4 } & $\mathrm{N}$ & 390 & 390 \\
\hline \multirow{3}{*}{ Tip eventraţie } & Pearson Correlation & $-.146^{* *}$ & 1 \\
\cline { 2 - 4 } & Sig. (2-tailed) & .004 & 390 \\
\cline { 2 - 4 } & $\mathrm{N}$ & 390 & \\
\hline \multirow{2}{*}{} & & & \\
\hline
\end{tabular}


Asocierea dintre herniile postincizionale complexe multisaculare şi gradul crescut de complicaţii evolutive a prezentat relevanţă statistică $(\mathrm{p}=0,004)$.

În ceea ce priveşte simptomatologia digestivă superioară de tipul vărsăturilor, aceasta a fost regăsită la 76,6\% dintre pacienţii cu hernii postincizionale complexe operaţi de urgenţă. S-a demonstrat relevanţa statistică a acestei asocieri cu modul de prezentare al bolnavilor $(\mathrm{p}=0,0001)$.

La participanţii la studiu, procesul supurativ cronic a fost întâlnit la $11,8 \%$ din totalul pacienţi- lor incluşi în lotul herniilor postincizionale complexe. Dintre aceştia, 3,6\% au necesitat intervenţia chirurgicală corectoare efectuată în urgență, iar $8,2 \%$ au fost admişi în spital în vederea unei intervenţii elective.

Este cunoscută în literatura de specialitate rata crescută de complicaţii postoperatorii, mai ales de tip infecţios, la pacienţii cu hernii postincizionale complexe operaţi de urgenţă.

În lotul de studiu, acestea au fost întâlnite la $18,1 \%$ dintre bolnavii operaţi în urgenţă, fără însă a se putea demonstra o corelaţie semnificativă sta-

TABEL 5A,B. Distribuția şi corelația distribuției simptomatologiei digestive superioare la pacienții operați în urgență

A. Distribuția simptomatologiei digestive superioare

\begin{tabular}{|c|c|c|c|c|c|}
\hline & & & \multicolumn{2}{|c|}{ Tipul operaţiei } & \multirow{2}{*}{ Total } \\
\hline & & & Elecţie & Urgenţă & \\
\hline \multirow{8}{*}{$\begin{array}{l}\text { Greaţă şi } \\
\text { vărsături }\end{array}$} & \multirow[t]{4}{*}{ Absentă } & Count & 236 & 23 & 258 \\
\hline & & $\begin{array}{l}\text { \% within Greaţă şi } \\
\text { vărsături }\end{array}$ & $91.5 \%$ & $8.5 \%$ & $100.0 \%$ \\
\hline & & $\begin{array}{l}\text { \% within Tipul } \\
\text { operaţiei }\end{array}$ & $79.7 \%$ & $23.4 \%$ & $66.2 \%$ \\
\hline & & $\%$ of Total & $60.5 \%$ & $5.6 \%$ & $66.2 \%$ \\
\hline & \multirow[t]{4}{*}{ Prezentă } & Count & 60 & 72 & 132 \\
\hline & & $\begin{array}{l}\text { \% within Greaţă şi } \\
\text { vărsături }\end{array}$ & $45.5 \%$ & $54.5 \%$ & $100.0 \%$ \\
\hline & & $\begin{array}{l}\% \text { within Tipul } \\
\text { operaţiei }\end{array}$ & $20.3 \%$ & $76.6 \%$ & $33.8 \%$ \\
\hline & & $\%$ of Total & $15.4 \%$ & $18.5 \%$ & $33.8 \%$ \\
\hline \multirow{4}{*}{\multicolumn{2}{|c|}{ Total }} & Count & 296 & 95 & 390 \\
\hline & & $\begin{array}{l}\text { \% within Greaţă şi } \\
\text { vărsături }\end{array}$ & $75.9 \%$ & $24.1 \%$ & $100.0 \%$ \\
\hline & & $\begin{array}{l}\text { \% within Tipul } \\
\text { operaţiei }\end{array}$ & $100.0 \%$ & $100.0 \%$ & $100.0 \%$ \\
\hline & & $\%$ of Total & $75.9 \%$ & $24.1 \%$ & $100.0 \%$ \\
\hline
\end{tabular}

B. Corelația distribuției simptomatologiei digestive superioare

\begin{tabular}{|l|l|c|c|}
\hline \multirow{4}{*}{ Tipul operaţiei } & & Tipul operaţiei & $\begin{array}{c}\text { Greaţă şi } \\
\text { vărsături }\end{array}$ \\
\cline { 2 - 4 } & Pearson Correlation & 1 & $.509^{* *}$ \\
\cline { 2 - 4 } & Sig. (2-tailed) & & .0001 \\
\cline { 2 - 4 } & $\mathrm{N}$ & 390 & 390 \\
\hline \multirow{2}{*}{$\begin{array}{l}\text { Greaţă şi } \\
\text { vărsături }\end{array}$} & Pearson Correlation & $.509^{* *}$ & 1 \\
\cline { 2 - 4 } & Sig. (2-tailed) & .0001 & 390 \\
\cline { 2 - 4 } & $\mathrm{N}$ & 390 & \\
\hline
\end{tabular}

**. Correlation is significant at the 0.01 level (2-tailed)

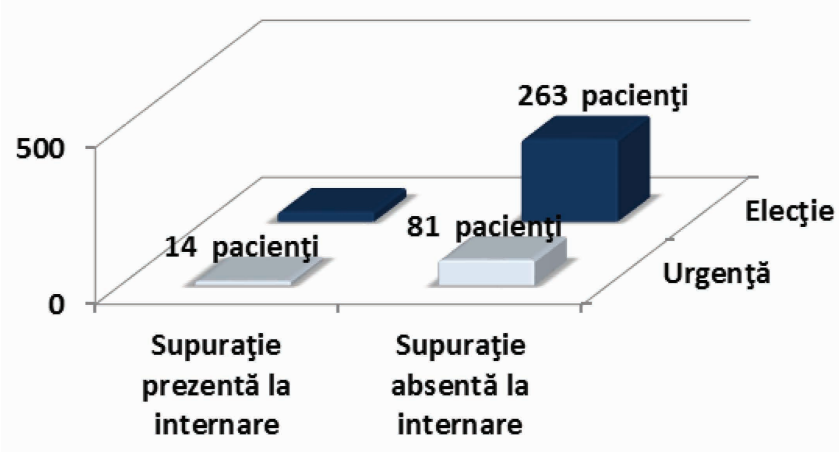

\section{$\checkmark$ Urgenţă}

E Elecţie
FIGURA 3. Asocierea procesului supurativ cronic cu prezentarea în urgență 
TABEL 6A,B. Distribuția şi corelația distribuției procesului supurativ cronic la pacienții operați în urgență

6A. Distribuția procesului supurativ cronic

\begin{tabular}{|c|c|c|c|c|c|}
\hline & & & \multicolumn{2}{|c|}{ Tipul operaţiei } & \multirow{2}{*}{ Total } \\
\hline & & & Elecţie & Urgenţă & \\
\hline \multirow{8}{*}{$\begin{array}{l}\text { Supuraţie } \\
\text { în } \\
\text { prezent }\end{array}$} & \multirow[t]{4}{*}{ Absentă } & Count & 264 & 80 & 344 \\
\hline & & $\begin{array}{l}\text { \% within Supuraţie în } \\
\text { prezent }\end{array}$ & $76.7 \%$ & $23.3 \%$ & $100.0 \%$ \\
\hline & & \% within Tipul operaţiei & $89.2 \%$ & $85.1 \%$ & $88.2 \%$ \\
\hline & & $\%$ of Total & $67.7 \%$ & $20.5 \%$ & $88.2 \%$ \\
\hline & \multirow[t]{4}{*}{ Prezentă } & Count & 32 & 15 & 46 \\
\hline & & $\begin{array}{l}\% \text { within Supuraţie în } \\
\text { prezent }\end{array}$ & $69.6 \%$ & $30.4 \%$ & $100.0 \%$ \\
\hline & & \% within Tipul operaţiei & $10.8 \%$ & $14.9 \%$ & $11.8 \%$ \\
\hline & & $\%$ of Total & $8.2 \%$ & $3.6 \%$ & $11.8 \%$ \\
\hline \multirow{4}{*}{\multicolumn{2}{|c|}{ Total }} & Count & 296 & 95 & 390 \\
\hline & & $\begin{array}{l}\% \text { within Supuraţie în } \\
\text { prezent }\end{array}$ & $75.9 \%$ & $24.1 \%$ & $100.0 \%$ \\
\hline & & \% within Tipul operaţiei & $100.0 \%$ & $100.0 \%$ & $100.0 \%$ \\
\hline & & $\%$ of Total & $75.9 \%$ & $24.1 \%$ & $100.0 \%$ \\
\hline
\end{tabular}

6B. Corelația distribuției procesului supurativ cronic

\begin{tabular}{|l|l|c|c|}
\hline Tipul operaţiei & & Tipul operaţiei & $\begin{array}{c}\text { Supuraţie în } \\
\text { prezent }\end{array}$ \\
\cline { 2 - 4 } & Pearson Correlation & 1 & .054 \\
\cline { 2 - 4 } & Sig. (2-tailed) & & .286 \\
\cline { 2 - 4 } & $\mathrm{N}$ & 390 & 390 \\
\hline \multirow{2}{*}{$\begin{array}{c}\text { Greaţă şi } \\
\text { vărsături }\end{array}$} & Pearson Correlation & .054 & 1 \\
\cline { 2 - 4 } & Sig. (2-tailed) & .286 & 390 \\
\cline { 2 - 4 } & $\mathrm{N}$ & 390 & \\
\hline
\end{tabular}

TABEL 7A,B. Distribuția şi corelația distribuției complicațiilor postoperatorii în funcție de caracterul intervenției

7A. Distribuția complicațiilor postoperatorii

\begin{tabular}{|c|c|c|c|c|c|}
\hline & & & \multicolumn{2}{|c|}{ Tipul operaţiei } & \multirow[b]{2}{*}{ Total } \\
\hline & & & Elecţie & Urgenţă & \\
\hline \multirow{8}{*}{$\begin{array}{l}\text { Complicaţii } \\
\text { postoperatorii }\end{array}$} & \multirow[t]{4}{*}{ Absente } & Count & 252 & 77 & 329 \\
\hline & & $\begin{array}{l}\% \text { within Complicaţii } \\
\text { postoperatorii }\end{array}$ & $76.6 \%$ & $23.4 \%$ & $100.0 \%$ \\
\hline & & \% within Tipul operaţiei & $85.1 \%$ & $81.9 \%$ & $84.4 \%$ \\
\hline & & $\%$ of Total & $64.6 \%$ & $19.7 \%$ & $84.4 \%$ \\
\hline & \multirow[t]{4}{*}{ Prezente } & Count & 44 & 18 & 61 \\
\hline & & $\begin{array}{l}\% \text { within Complicaţii } \\
\text { postoperatorii }\end{array}$ & $72.1 \%$ & $27.9 \%$ & $100.0 \%$ \\
\hline & & \% within Tipul operaţiei & $14.9 \%$ & $18.1 \%$ & $15.6 \%$ \\
\hline & & $\%$ of Total & $11.3 \%$ & $4.4 \%$ & $15.6 \%$ \\
\hline \multirow{4}{*}{\multicolumn{2}{|c|}{ Total }} & Count & 296 & 95 & 390 \\
\hline & & $\begin{array}{l}\% \text { within Complicaţii } \\
\text { postoperatorii }\end{array}$ & $75.9 \%$ & $24.1 \%$ & $100.0 \%$ \\
\hline & & \% within Tipul operaţiei & $100.0 \%$ & $100.0 \%$ & $100.0 \%$ \\
\hline & & $\%$ of Total & $75.9 \%$ & $24.1 \%$ & $100.0 \%$ \\
\hline
\end{tabular}

7B. Corelația distribuției complicațiilor postoperatorii

\begin{tabular}{|l|l|l|l|}
\hline \multirow{4}{*}{ Tipul operaţiei } & & Tipul operaţiei & Complicaţii postoperatorii \\
\cline { 2 - 4 } & Pearson Correlation & 1 & .038 \\
\cline { 2 - 4 } & Sig. (2-tailed) & & .455 \\
\cline { 2 - 4 } & $\mathrm{N}$ & 390 & 390 \\
\hline \multirow{4}{*}{$\begin{array}{c}\text { Complicaţii } \\
\text { postoperatorii }\end{array}$} & Pearson Correlation & .038 & 1 \\
\cline { 2 - 4 } & Sig. (2-tailed) & .455 & \\
\cline { 2 - 4 } & $\mathrm{N}$ & 390 & 390 \\
\hline
\end{tabular}


tistic între modul de prezentare şi factorul septic preexistent $(\mathrm{p}=0,286)$.

În lotul herniilor postincizionale complexe, complicaţiile postoperatorii au fost întâlnite la $18,1 \%$ dintre bolnavii operaţi în urgenţă (8 dintre pacienţii la care a fost utilizat un procedeu reparator aloplastic şi 9 dintre pacienţii cu herniorafie în manieră tisulară) şi la 14,9\% dintre pacienţii operaţi electiv, fără a se putea determina o relevanţă statistică a acestei asocieri în studiul de faţă $(p=0,455)$.

În ceea ce priveşte complicaţiile postoperatorii cu risc vital, acestea au fost regăsite la 18 dintre pacienţii operaţi în urgenţă, fiind asociate în mod relevant statistic cu modul de prezentare $(p=0,0001)$.

TABEL 8A,B. Distribuția şi corelația distribuției deceselor la pacienții operați în urgență

\section{A. Distribuția deceselor}

\begin{tabular}{|c|c|c|c|c|c|}
\hline & \multicolumn{2}{|c|}{ Tipul operaţiei } & \multirow{2}{*}{ Total } \\
\hline & & & Elecţie & Urgenţă & \\
\hline \multirow{8}{*}{ Deces } & \multirow{4}{*}{$\mathrm{Nu}$} & Count & 294 & 87 & 380 \\
\hline & & $\%$ within Deces & $77.4 \%$ & $22.6 \%$ & $100.0 \%$ \\
\hline & & $\begin{array}{l}\% \text { within Tipul } \\
\text { operaţiei }\end{array}$ & $99.3 \%$ & $91.5 \%$ & $97.4 \%$ \\
\hline & & $\%$ of Total & $75.4 \%$ & $22.1 \%$ & $97.4 \%$ \\
\hline & \multirow{4}{*}{$\mathrm{Da}$} & Count & 2 & 8 & 10 \\
\hline & & $\%$ within Deces & $20.0 \%$ & $80.0 \%$ & $100.0 \%$ \\
\hline & & $\begin{array}{l}\% \text { within Tipul } \\
\text { operaţiei }\end{array}$ & $0.7 \%$ & $8.5 \%$ & $2.6 \%$ \\
\hline & & $\%$ of Total & $0.5 \%$ & $2.1 \%$ & $2.6 \%$ \\
\hline \multirow{4}{*}{\multicolumn{2}{|c|}{ Total }} & Count & 296 & 95 & 390 \\
\hline & & $\%$ within Deces & $75.9 \%$ & $24.1 \%$ & $100.0 \%$ \\
\hline & & $\begin{array}{l}\% \text { within Tipul } \\
\text { operaţiei }\end{array}$ & $100.0 \%$ & $100.0 \%$ & $100.0 \%$ \\
\hline & & $\%$ of Total & $75.9 \%$ & $24.1 \%$ & $100.0 \%$ \\
\hline
\end{tabular}

8B. Corelația distribuției deceselor

\begin{tabular}{|l|l|c|c|}
\hline \multirow{3}{*}{$\begin{array}{l}\text { Tipul } \\
\text { operaţiei }\end{array}$} & & Tipul operaţiei & Deces \\
\cline { 2 - 4 } & Pearson Correlation & 1 & $.212^{* *}$ \\
\cline { 2 - 4 } & Sig. (2-tailed) & & .0001 \\
\cline { 2 - 4 } & $\mathrm{N}$ & 390 & 390 \\
\hline \multirow{3}{*}{ Deces } & Pearson Correlation & $.212^{* *}$ & 1 \\
\cline { 2 - 4 } & Sig. (2-tailed) & .0001 & \\
\cline { 2 - 4 } & $\mathrm{N}$ & 390 & 390 \\
\hline
\end{tabular}

TABEL 9. Complicațiile postoperatorii în lotul herniilor postincizionale complexe operate în urgență

\begin{tabular}{|l|l|l|l|}
\hline Complicaţii & Urgenţă & Tisular & Aloplastic \\
\hline Granulom de fir & 0 & 0 & 0 \\
\hline Hematom & 1 & 0 & 1 \\
\hline Fasceită necrozantă- deces & 1 & 1 & 0 \\
\hline $\begin{array}{l}\text { Sindrom de compartiment - } \\
\text { deces }\end{array}$ & 5 & 4 & 1 \\
\hline $\begin{array}{l}\text { Abces retroperitoneal } \\
\text { parastomal }\end{array}$ & 1 & 0 & 1 \\
\hline Supuraţie plagă & 6 & 1 & 5 \\
\hline Peritonită - MSOF-Deces & 2 & 2 & 0 \\
\hline Fistulă enterală, supuraţie & 1 & 1 & 0 \\
\hline
\end{tabular}

Luând în discuţie procedeul chirurgical utilizat în tratamentul de urgenţă al herniilor postincizionale complexe, protezarea a fost considerată oportună şi utilizată la 54\% dintre pacienţi.

Dintre aceştia, la 45 de cazuri a fost utilizată protezarea retromusculară Rives-Stoppa, montarea intraperitoneală a protezei la 4 cazuri şi protezarea intraperitoneală şi supraaponevrotică la câte un caz.

TABEL 10. Procedee reparatorii utilizate în chirurgia de urgență a herniilor postincizionale complexe

\begin{tabular}{|c|c|c|c|c|}
\hline Tisular & \multicolumn{4}{|c|}{ Aloplastic } \\
\hline \multirow{3}{*}{44} & Rives- & Properi- & Supra- & Intra \\
& Stoppa & toneal & aponevrotic & peritoneal \\
& 45 & 4 & 1 & 1 \\
\hline
\end{tabular}

\section{DISCUTुII}

Studiul prezent este un argument în favoarea chirurgiei protetice a herniilor postincizionale complexe şi urmăreşte identificarea problemelor de tehnică şi tactică cu care se confruntă chirurgul, mai ales atunci când este obligat să efectueze tratamentul acestei patologii în condiţii de urgenţă, luând în discuție un bolnav dezechilibrat, cu comorbidităţi şi de multe ori cu necesitate de rezecţii intestinale $(7,11)$.

În ceea ce priveşte simptomatologia pacienţilor ce se prezintă la spital în momentul apariţiei complicaţiilor şi care necesită tratament chirurgical de urgenţă, au fost regăsite simptomatologia algică, simptomatologia ocluzivă digestivă superioară sau inferioară, date comparabile cu cele prezente în literatură $(10,25)$.

Discutând despre prezenţa procesului supurativ cronic preexistent, deşi în literatură este raportată o rată mai mare de complicaţii postoperatorii $(3,10,11,19,27)$, nu am demonstrat o asociere semnificativă statistic între acest factor şi dezvoltarea complicaţiilor postoperatorii.

Complicaţiile postoperatorii au fost regăsite la $18,1 \%$ dintre pacienţii operaţi în urgenţă $(9,58 \%$ dintre pacienţii operaţi tisular şi 8,52 dintre pacienţii la care au fost utilizate materialele protetice) (21), într-o proporţie mai scăzută comparativ cu $23,6 \%$ în studiile din literatură $(7,14,17,19,28)$.

Deşi complicaţiile postoperatorii au fost întâlnite într-un număr mai mic, în schimb, complicaţiile vitale au reprezentat $8,5 \%$ din totalul acestora (4,9\% în literatură) (28).

Dat fiind faptul că herniile postincizionale apar în proporţie de $74 \%$ în primii 3 ani de la intervenţia chirurgicală, durata de desfăşurare a studiului reprezintă un punct forte în termeni de urmărire 
postoperatorie pentru identificarea complicaţiilor şi recidivelor. De asemenea, înrolarea unui număr mare de pacienţi şi folosirea în mod similar a tehnicilor de herniorafie tisulară şi aloplastică permit compararea şi generarea unor concluzii pertinente în termeni de complicaţii postoperatorii ale celor două tehnici.

Dintre limitările studiului, amintim faptul că este un studiu unicentric, desfăşurat într-o populaţie dintr-un centru universitar, unde pacienţii pot avea acces facil la serviciile medicale şi materialele protetice necesare unei reparaţii herniare. Această situaţie poate varia la nivelul întregii ţări sau în zone cu acces limitat la serviciile de sănătate.

De asemenea, ca limitare a studiului, menţionăm indisponibilitatea utilizării curente a bioprotezelor, în studiu fiind înrolaţi doar pacienţii la care au fost folosite proteze de polipropilenă montatate intratecal sau supraaponevrotic şi pacienţii la care au fost folosite proteze montate intraperitoneal.

\section{CONCLUZII}

Pacienţii cu hernii postincizionale complexe reprezintă o particularitate, atât din punctul de vedere al abordării chirurgicale prin dimensiunile defectului parietal sau al localizării acestuia, cât şi

Conflict of interest: none declared

Financial support: none declared

\section{BIBLIOGRAFIE}

1. Bernard C, Polliand C, Mutelica L, Champault G. Repair of giant incisional abdominal wall hernias using open intraperitoneal mesh. Hernia. 2007 Aug;11(4):315-20.

2. Yahchouchy-Chouillard E, Aura T, Picone O, Etienne JC, Fingerhut A. Incisional hernias. I. Related risk factors. Dig Surg. 2003; 20(1):3-9. doi:

3. Alaedeen DI, Lipman J, Medalie D, Rosen MJ. The single-staged approach to the surgical management of abdominal wall hernias in contaminated fields. Hernia. $2007 \mathrm{Feb} ; 11(1): 41-5$.

4. Llama and Alpaca Care: Medicine, Surgery, Reproduction, Nutrition, and Herd Health: First Edition. Elsevier Inc., 2013.

5. Wong SY, Kingsnorth AN. Abdominal Wound Dehiscence and Incisional Hernia. Surgery (Oxford). 2002;20(5):100-103.

6. Sharma RK, Singh G, Naidu PM. Abdominal wall defects: anatomic classification and a scheme for management. Ann Plast Surg. 1998 Aug;41(2):180-4.

7. Zafar H, Zaidi M, Qadir I, Memon AA. Emergency incisional hernia repair: a difficult problem waiting for a solution. Ann Surg Innov Res. 2012 Jan 4;6(1):1.

8. Birolini C, de Miranda JS, Tanaka EY, Utiyama EM, Rasslan S, Birolini D. The use of synthetic mesh in contaminated and infected abdominal wall repairs: challenging the dogma-A long-term prospective clinical trial. Hernia. 2020 Apr;24(2):307-323.

9. Petersson J, Koedam TW, Bonjer HJ, Andersson J, Angenete E, Bock D, et al.; COlorectal cancer Laparoscopic or Open Resection (COLOR) II Study Group. Bowel Obstruction and Ventral Hernia After Laparoscopic Versus Open Surgery for Rectal Cancer in A Randomized Trial (COLOR II). Ann Surg. 2019 Jan;269(1):53-57.

10. Rosen MJ, Krpata DM, Ermlich B, Blatnik JA. A 5-year clinical experience with single-staged repairs of infected and contaminated prin patologia asociată, fapt ce impune o abordare individualizată a bolnavului.

Atât prezentarea în urgenţă a pacienţilor cunoscuţi cu defecte herniare complexe, care impun rezolvarea imediată din cauza complicaţiilor ocluzive intestinale, cât şi lipsa stabilizării patologiei de fond, riscul reparaţiei herniare în condiţii contaminate, cu necesar de rezecţii intestinale şi de multe ori cu imposibilitatea corectării aloplastice a defectului, ar trebui să ne ridice un semnal de alarmă în ceea ce priveşte informarea şi educaţia medicală a bolnavilor.

$\mathrm{Cu}$ toate acestea, utilizarea protezării parietale în tratamentul de urgenţă al patologiei herniare postincizionale complexe nu s-a dovedit a fi de evitat, având rate similare în ceea ce priveşte complicaţiile de plagă şi complicaţiile vitale, ci mai degrabă trebuie utilizată judicios, pentru obţinerea dezideratului de "tension-free".

Creşterea gradului de informare şi educare a pacientului, creşterea adresabilităţii, evitarea prezentării şi soluţionării patologiei herniare în condiţii de urgenţă, în momentul apariţiei complicaţiilor ocluzive, reprezintă obiective pe termen lung în tratamentul patologiei herniare postincizionale complexe.

abdominal wall defects utilizing biologic mesh. Ann Surg. 2013 Jun;257(6):991-6.

11. López-Cano M, Quiles MT, Pereira JA, Armengol-Carrasco M, Arbós Vía MA. Complex Abdominal Wall Hernia Repair in Contaminated Surgical Fields: Factors Affecting the Choice of Prosthesis. Am Surg. 2017 Jun 1;83(6):583-590.

12. Halm JA, Lip H, Schmitz PI, Jeekel J. Incisional hernia after upper abdominal surgery: a randomised controlled trial of midline versus transverse incision. Hernia. 2009 Jun;13(3):275-80.

13. Henriksen NA, Yadete DH, Sorensen LT, Agren MS, Jorgensen LN. Connective tissue alteration in abdominal wall hernia. Br J Surg. 2011 Feb;98(2):210-9.

14. Pandey $H$, Thakur DS, Somashekar U, Kothari R, Agarwal P, Sharma D. Use of polypropylene mesh in contaminated and dirty strangulated hernias: short-term results. Hernia. 2018 Dec;22(6):1045-1050.

15. Burger JW, Luijendijk RW, Hop WC, Halm JA, Verdaasdonk EG, Jeekel J. Long-term follow-up of a randomized controlled trial of suture versus mesh repair of incisional hernia. Ann Surg. 2004 Oct;240(4):578-85.

16. Temudom T, Siadati M, Sarr MG. Repair of complex giant or recurrent ventral hernias by using tension-free intraparietal prosthetic mesh (Stoppa technique): lessons learned from our initial experience (fifty patients). Surgery. 1996 Oct;120(4):738-44.

17. Maatouk M, Ben Safta Y, Mabrouk A, Kbir GH, Ben Dhaou A, Sami Daldoul, Sayari S, Haouet K, Dziri C, Ben Moussa M. Surgical site infection in mesh repair for ventral hernia in contaminated field: A systematic review and meta-analysis. Ann Med Surg (Lond). 2021 Feb 12;63:102173.

18. Baumann DP, Butler CE. Bioprosthetic mesh in abdominal wall reconstruction. Semin Plast Surg. 2012 Feb;26(1):18-24. 
19. Brandt CP, McHenry CR, Jacobs DG, Piotrowski JJ, Priebe PP. Polypropylene mesh closure after emergency laparotomy: morbidity and outcome. Surgery. 1995 Oct;118(4):736-41.

20. Berger RL, Li LT, Hicks SC, Davila JA, Kao LS, Liang MK. Development and validation of a risk-stratification score for surgical site occurrence and surgical site infection after open ventral hernia repair. J Am Coll Surg. 2013 Dec;217(6):974-82.

21. Hodgkinson JD, Maeda Y, Leo CA, Warusavitarne J, Vaizey CJ. Complex abdominal wall reconstruction in the setting of active infection and contamination: a systematic review of hernia and fistula recurrence rates. Colorectal Dis. 2017 Apr;19(4):319-330.

22. Pereira JA, Montcusí $B$, López-Cano M, Hernández-Granados $P$, Fresno de Prado L; Miembros del registro EVEREG. Risk factors for bad outcomes in incisional hernia repair: Lessons learned from the National Registry of Incisional Hernia (EVEREG). Cir Esp (Engl Ed). 2018 Aug-Sep;96(7):436-442.

23. Chevrel JP, Rath AM. Classification of incisional hernias of the abdominal wall. Hernia. 2000;4:7-11.
24. Hesselink VJ, Luijendijk RW, de Wilt JH, Heide R, Jeekel J. An evaluation of risk factors in incisional hernia recurrence. Surg Gynecol Obstet. 1993 Mar;176(3):228-34.

25. Mutwali IM. Incisional hernia: Risk factors, incidence, pathogenesis, prevention and complications. Sudan Med Monit. 2014;9(2):81-6.

26. Kaoutzanis C, Leichtle SW, Mouawad NJ, Welch KB, Lampman RM, Wahl WL, Cleary RK. Risk factors for postoperative wound infections and prolonged hospitalization after ventral/incisional hernia repair. Hernia. 2015 Feb;19(1):113-23.

27. Walming S, Angenete E, Block M, Bock D, Gessler B, Haglind E. Retrospective review of risk factors for surgical wound dehiscence and incisional hernia. BMC Surg. 2017 Feb 22;17(1):19.

28. Derici H, Unalp HR, Bozdag AD, Nazli O, Tansug T, Kamer E. Factors affecting morbidity and mortality in incarcerated abdominal wall hernias. Hernia. 2007 Aug;11(4):341-6. 